\title{
UNCERTAINTY AND INVESTMENT IN PRECISION AGRICULTURE - IS IT WORTH THE MONEY?
}

\author{
P. R. Tozer \\ Muresk Institute of Agriculture, \\ Curtin University of Technology. \\ Northam, Western Australia, Australia.
}

\begin{abstract}
Irreversibility and uncertainty render the standard capital budgeting techniques such as net present value (NPV) analysis insufficient as a decision criterion. The standard NPV underestimates the value of the investment by not including the value of waiting for new information to reduce the uncertainty of the cashflows generated by the investment. An alternative to NPV analysis is real options. In this study we apply real options analysis to an investment decision for a grain producer in Western Australia. The investment choice is to purchase machinery suitable for undertaking controlled traffic precision agriculture or acquire a conventional system and reduce sowing time. The results of the analysis suggest that the required rates of return for the two investment alternatives need to be approximately 20-40 \% higher than the returns estimated by the standard NPV analysis. These higher rates of return are required to compensate for the uncertainty inherent in the cropping systems of the farm. Also, in most cases, even though the variable costs of operating the precision agriculture system were higher, due to smaller operating widths, the additional returns generated by managing zones individually outweighed these additional costs. Further analysis also shows that the relative size of management zones has a marked effect on the returns generated and that it is possible to increase returns by taking out marginally productive zones.
\end{abstract}

Keywords - Investment analysis Real options Uncertainty Economics.

\section{INTRODUCTION}

Many studies on the economics of precision agriculture or variable rate technology have focussed on paddock-level analysis and considered the variable inputs, such as fertilizer, and outputs (grain) generated in the farming system, see for example Babcock and Pautsch (1998) or James and Godwin (2003) and have not explicitly considered the investment in machinery and technology of the farming system. Very few studies have examined the costs of investing in 
precision agriculture technology or compared the costs of conventional farming technology to the precision agriculture technology on a whole farm basis. Although the machinery necessary to undertake variable rate operations is similar to that for conventional systems the costs of swapping to the precision agriculture system can be substantial.

Several challenges arise when examining the capital investment problem for any decision maker these are uncertainty and irreversibility. The first of these is the uncertainty associated with the production system in which the capital is to be employed. In the context of the farming problem uncertainty can arise from within the physical production system, i.e. production risk, or the marketing system, i.e. price risk (Sonka and Patrick 1984). Production risk arises from many different aspects, but two components of production risk in a field are spatial and temporal variability. Spatial variability, i.e. changes in crop response to soil type across a field, is the basis for much of the emphasis of precision agricultural research and variable rate technology applications. Temporal variability is caused by variations across production years due to climatic or seasonal factors, such as rainfall or frost events. The second of the challenges for a decision maker is the reversibility or irreversibility of the decision to be made and the costs associated with this challenge.

Standard investment analyses, such as net present value (NPV) calculations assume that prices and yields are known with certainty and that the investment can be reversed without any costs, which in most cases is not true. Even simple investments incur some sunk costs that cannot be recovered (Dixit and Pindyck 1994). To overcome the problems of uncertainty and irreversibility in the capital investment decision, Dixit (1992) proposed an alternative method that captures the uncertainty and costs of irreversibility of an investment; this method is real options analysis. Real options analysis allows a decision maker to build uncertainty, irreversibility, and the ability to wait to make a decision into one framework and determine the impact these three factors have on the profitability of the decision. The value of waiting to invest, the option part of the analysis, provides the value to the investor of waiting to gather more information to reduce the level of uncertainty or reduce the costs of irreversibility (Dixit and Pindyck 1994).

\section{METHOD}

\section{Real options}

In the standard NPV investment analysis the investment is considered worthwhile if the discounted value of the stream of returns from the investment exceeds the initial cost incurred to generate that stream of returns. However, it is assumed in the NPV process that future costs and returns are known with certainty and that it is possible to recover the initial costs of the investment, i.e. certainty and reversibility are implicit in the NPV analysis (Purvis et al. 1995). In reality many investments are not reversible, for example, factory buildings, or industry or firm specific inputs, such as fertiliser or pasture seed once used cannot be reused or recovered. Also, returns for many products, particularly agricultural

products are highly variable on a year-to-year basis. For example, the mean real 
annual price for wheat in Australia over the period 1980 to 2006 was \$227/t with a standard deviation of \$27/t (ABARE 2006).

Because of uncertainty and irreversibility, Dixit (1992) proposed an alternative method of capital budgeting that incorporates uncertainty and irreversibility based on the decision-maker's option to delay investment. Delaying investment may be optimal, as time is required to resolve uncertainty. Dixit (1992) called his theory real option theory; real options requires knowledge of four parameters: the expected returns from the investment, $R$; the sunk costs of the investment, $K$; the risk-adjusted discount rate, $\rho$; and the variance of the logarithm of the expected returns, $\sigma^{2}$.

Dixit (1992) demonstrated that the optimal timing of an investment is when the strategic value of the investment is just equal to the NPV of the investment implying the option to delay investment is zero. The strategic value of an investment consists of both the NPV of the investment and the option to delay investment. Brought on by uncertainty and irreversibility, the option to delay investment implies that a positive NPV is no longer a sufficient condition for undertaking an investment. Figure 1 shows a simplified real option scenario where the (perpetual) net cash flows from an investment are on the $\mathrm{x}$-axis and value of the investment is on the y-axis. For a perpetuity, the net present value is simply:

(1) $V=R / \rho-K$,

Where $\mathrm{R}$ represents the perpetual expected net cash flows of the investment, $\mathrm{K}$ is the initial cost of the investment, and $\rho$ is the discount rate. As shown, the $i_{1} i_{2}$ line is linear with a positive slope, $1 / \rho$, indicates that as the net cash flows increase, so does the net present value. Notice that when $R=0, V=-K$ implying the net present value is just the cost of the investment. Also notice that at $R=M$, $V=M / \rho-K=0$ so that net cash flows are just large enough for the investment to break even. At $R=M$, we also have $\rho=M / K$ with the interpretation that $\rho$ is the "hurdle" rate, or the minimum rate an investment must return for it to be acceptable. For any value of $R$ greater than $M$ the investment will generate returns that more than cover the costs of the investment, i.e. it is a profitable investment.

Also plotted in Figure 1 is the strategic investment value curve $F(V)$ labelled $\mathrm{w}_{1} \mathrm{w}_{2}$. Mathematically, Dixit (1992) has shown that:

$$
\text { (2) } \mathrm{F}(\mathrm{V})= \begin{cases}M / \rho-K & \mathrm{~V} \geq \mathrm{V}^{*}(\text { or } \mathrm{R} \geq \mathrm{H}) \\ A V^{\beta} & \mathrm{V} \leq \mathrm{V}^{*}(\text { or } \mathrm{R} \leq \mathrm{H})\end{cases}
$$

Here, $A$ and $\beta$ are constants with $A(\beta)$ determining the position of the curve (determining the slope of the curve). The transition from the curved line $w_{1} w_{2}$ to the linear line $i_{1} i_{2}$ at $H$ is often referred to as the "smooth pasting" condition in option pricing theory. Recall, the strategic value of an investment consists of both net present value and option value. Therefore, as long as $R<H$, the value of the option to delay investment is positive and the investment should not be undertaken. Most critical in real option theory are net cash flows such that $M<R$ $<H$ since these levels induce positive net present value, but no investment should take place since the option to delay investment has value. Holding everything 


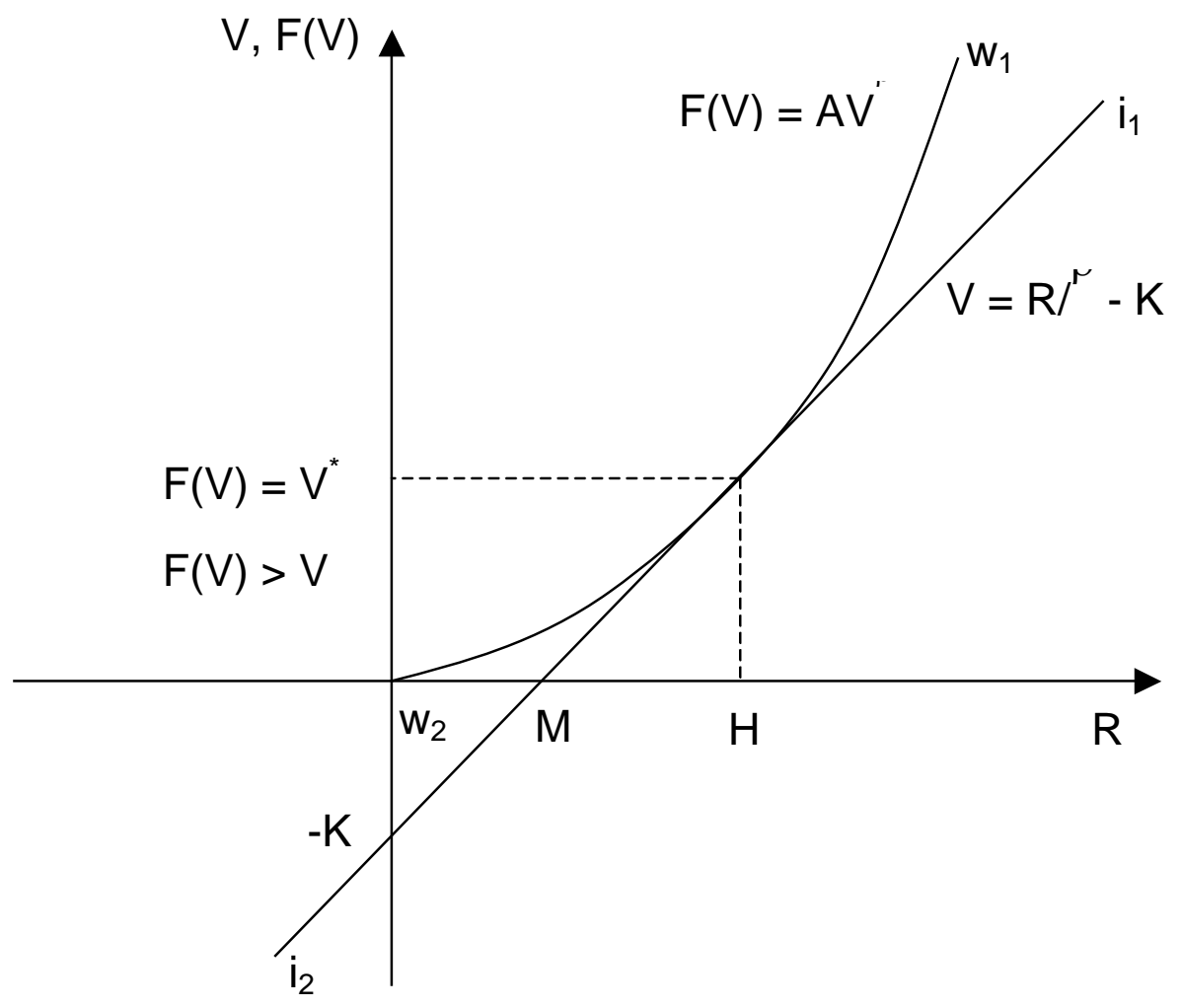

Fig 1. Optimal investment policy comparing real options analysis and a standard net present value technique.

else constant, only net cash flows of $R \geq H$ effectively extinguish the option to wait suggesting immediate investment should take place.

The smooth-pasting and value-matching conditions are simultaneously satisfied when;

(3) $H=(\beta /(\beta-1)) / \rho K$

Now the value of investing has increased from $\mathrm{M}$ to $\mathrm{H}$ by the factor $(\beta /(\beta-1))$ due to the uncertainty of the investment. The parameter $\beta$ captures the uncertainty of the investment through the inclusion of the variance of the logarithm of expected returns, $\sigma^{2}$ in the equation to calculate $\beta$ :

(4) $\beta=\frac{1}{2}\left[1+\sqrt{1+\frac{8 \rho}{\sigma^{2}}}\right]$

The value of $\beta$ is affected by the discount rate, $\rho$, and $\sigma^{2}$. As uncertainty increases ( $\sigma^{2}$ increases) the value of $\beta$ falls, this increases the required returns from the investment, lifts the value of waiting, and enlarges the difference between the NPV valuation of the investment, $M$, and $H$. Conversely, increasing the discount rate, making earlier returns more valuable than later returns, lowers the value of $\beta$ and moves $H$ closer to $M$.

Dixit (1992) proposed that a measure that captures the uncertainty of an investment is the "modified hurdle" rate. This is the minimum rate at which an 
uncertain investment needs to return for it to be profitable and captures the value of waiting to invest. The modified hurdle rate is defined as:

(5) $\rho^{\prime}=(\beta /(\beta-1)) / \rho$

This modified hurdle rate can then be used to amend the investment trigger. The modified investment trigger is now:

(6) $H=\rho^{\prime} K$

The modified trigger is now used as the basis for determining whether a project should go ahead under uncertainty and irreversibility. The next challenge is to estimate the value of $\sigma^{2}$.

\section{Ex Ante Simulation Method to Estimate $\sigma^{2}$.}

One of the problems facing researchers is how to estimate the expected returns of an investment that has not occurred. It is possible to use cross-sectional ex post data to estimate an econometric model and the associated variance components (Purvis et al. 1995). However, as discussed in Purvis et al. (1995) the type of data required for an econometric model is usually unavailable, hence the need to undertake an ex ante simulation approach to estimate the data required. In the following discussion only the relevant information from Purvis et al. (1995) will be provided; for a full discussion see the original paper.

The returns from the investment, $V$, were assumed to follow a geometric Brownian motion process, Dixit and Pindyck (1994). This can be represented as:

$$
\text { (7) } \frac{d V}{V}=\mu d t+o d z \text {, }
$$

where $\mu$ is the expected rate of growth of the investment over the period of time $(d t)$ and $\sigma$ is the standard deviation rate of the growth rate of returns over the same time period, and $d z$ represents an increment of the Brownian motion $z(t)$ (Hyde et al. 2003).

Purvis et al. (1995) used a Taylor series expansion to show that:

$$
\frac{d V}{V}=\frac{\Delta V / \Delta t}{V}=\frac{1}{V} \times \frac{\Delta V}{\Delta t}=\frac{\Delta \ln (V)}{\Delta t}
$$

$$
=\ln \left(V_{n}\right)-\ln \left(V_{n-1}\right)=\Delta \ln \left(V_{n}\right)
$$

By simulating $V_{\mathrm{n}}$ and $V_{\mathrm{n}-1}$ we can estimate a variance for $\Delta \ln \left(V_{\mathrm{n}}\right)$ that is an approximation for $\sigma^{2}$. This approximation of the variance can be used to estimate $\beta$ and the modified hurdle rate $\rho^{\prime}$. $V_{\mathrm{n}}$ is calculated as follows:

(9)

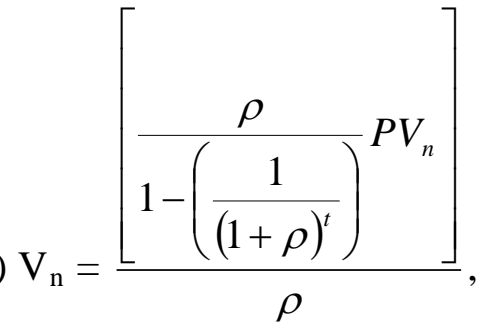

Where $P V_{\mathrm{n}}$ is the present value of the investment in the $n$th period of the investment, the value in brackets converts the present value into an annuity equivalent value, and dividing by the discount rate turns that annuity equivalent 
into a perpetual annuity value, i.e. the annuity value that would be received from the investment in perpetuity. The major assumption in this part of the process is that the investment can be reinitiated for another $n$ periods with the same sunk costs, $K$, as the current project (Purvis et al. 1995).

To estimate $V_{\mathrm{n}}$ and $V_{\mathrm{n}-1}$, hence $\sigma^{2}$, and the modified hurdle rate, a simulation model of the cashflows from each of the two potential investment opportunities was undertaken.

\section{Model}

The non-stochastic model is an EXCEL-based workbook that calculated the NPV of the two investments, with the investment period being 6 years and the discount rate equal to $9 \%$. The discount rate is the current nominal interest rate (ABARE 2006). Eighteen sets of identical gross margins were constructed for each of the two enterprises. Eighteen gross margins are required to cover three different management zones, described subsequently, within each of the two farming systems for the six years in the analysis period. Six years was chosen as the investment period as this is the average age of the harvester before it is traded in on a new model, (Tozer 2006). Each gross margin represented one year in the investment and this allowed for independent Monte Carlo simulations for each year for the parameters under uncertainty. To estimate the impact of uncertainty in the model and the variance of the logarithm of the expected returns 10,000 Monte Carlo simulations were undertaken using Crystal Ball 2000 Professional Edition. As $V$ is distributed log-normally due to assumption that $V$ follows a geometric Brownian motion process then it was assumed that for all continuous probability distributions used in the simulation they were also log-normally distributed. This assumption excludes the distribution of $d z$, which is distributed as $\mathrm{N}(0, d t)$.

Two sets of three models were run. The first set was an analysis of the impact that different relative sized zones would have on the investment decision. There were three size comparisons. The first was when there were three equally sized management zones across the farm (EA). The second set examined the effect that a zone arrangement of $50 \%$ of the farm area had high level of productivity, 30\% medium productivity, and $20 \%$ of the farm had low productivity $(\mathbf{5 0 H})$. The third subset inverted the second analysis; that is $20 \%$ high, $30 \%$ medium, and $50 \%$ low $(\mathbf{2 0 H})$. Although other combinations could have been tested it was decided that these three arrangements provided sufficient information for analysis and comparison. The second set of models examined the impact that dropping the low zone out of production would have on the relative investments. This decision was based on the distribution of returns for the low zone, particularly in the conventional system. The same set of zone arrangements as in the first analysis was used, i.e. equal areas (EANL), 50:30:20 high (50HNL), medium and low management zones, respectively, and 20:30:50 high (20HNL), medium and low management zones, respectively. 


\section{Case Study Farm}

The case study farm is located approximately $450 \mathrm{~km}$ north east of Perth in Western Australia. The farm has a total arable area of 3,300 ha of which $80 \%$ is sown to crop every year. Of the 2,600 ha sown $30 \%$ or 780 ha is sown to lupins and the remaining area is sown to wheat or barley, however wheat is preferred due to the higher returns. The lupin crop is sown as a break crop and a source of nitrogen, in the model it is assumed that the returns from lupins are fixed at a gross margin of $\$ 70 /$ ha as no trial data was available for lupin yield or quality.

\section{Machinery Characteristics.}

Given that, in reality, investing in production capital such as machinery is an incremental process and that there are many combinations and permutations for machinery purchases it would not be possible to capture the process in a relatively simple model. Therefore, it is assumed in this study that the producer purchases a full set of machinery suitable for all operations on the case study farm. For the precision agriculture system the machinery is based on matching to a $9.1 \mathrm{~m} \mathrm{(30 \textrm {ft } )}$

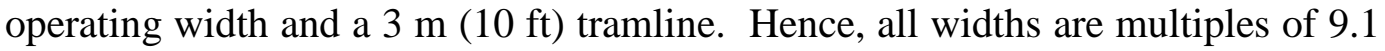
$\mathrm{m}$, the harvester has a $9.1 \mathrm{~m}$ front, the boomspray is $27.3 \mathrm{~m}$, and the air seeder bar is $9.1 \mathrm{~m}$ and the airseeder capacity is six tonnes. Two tractors are also assumed to be purchased, one a tracked tractor and the other is a four-wheeled drive one. Because of the $3 \mathrm{~m}$ tramline it is necessary to install axle extensions on both tractors and these are included in the total purchase price. Two additional purchases are also included and these are a $25 \mathrm{~T}$ chaser bin for harvest and a fertiliser spreader with a spread width of $9.1 \mathrm{~m}$. Axle extensions are not necessary for the chaser bin, but are required for the spreader. All tractors and the harvester are fitted with autosteer and two movable GPS units are also purchased, these have two-centimetre accuracy for the tramlining system, and an annual satellite subscription is also purchased. The spreader and seeder bar are also fitted with controllers to allow for variable rate applications of fertiliser at sowing and during the growing season. The total purchase cost of the precision package was $\$ 1,403,100$. Using this value, standard straight-line depreciation rates, a $6 \%$ real interest rate and $2 \%$ repair cost rate (NSWDPI 2007), the annual cost of operating the machinery was $\$ 113 /$ ha.

For the conventional system, i.e. round and round, it is assumed that the machinery purchased has the capacity to complete crop sowing in approximately two to three weeks, the ideal sowing window for the case study area. In this conventional system a harvester with an $11 \mathrm{~m}$ (36 ft) front was assumed. One larger seeding tractor, and airseeder (nine tonnes and $18.3 \mathrm{~m}$ ), and a similar sized tractor and sprayer to the precision system, were also included in the conventional package. The total cost for this package was $\$ 1,435,000$. Using the same depreciation and operating cost parameters the annual machinery cost for the conventional system was \$104/ha. The operating cost is lower than for the precision agriculture system due to faster operating speeds at sowing, spraying and harvesting even though the purchase cost was slightly higher incurring higher depreciation and interest costs. However, due to operating inefficiencies such as

overlaps and higher power needed for sowing operations the operating costs were 
increased by 5\%, this is consistent with reported experimental results (Blackwell et al. 2003).

\section{Grain yield and quality data.}

Based on several trials on the case study farm it is assumed the farm has three soil types and because of the soil types three different input management zones. The three management zones are simply labelled high, medium and low, reflecting both the productivity and input levels for each zone. The productivity and input levels for each zone are based on the reported trial results and one year's worth of unreported data, (Webb et al., 2005; Isbister et al., 2006). The trial period covers years of average and high productivity and for the year 2006, the lowest rainfall year recorded in the region of the case study farm. Hence, although the data set is relatively small the variability of the data is representative of the potential production in the region, thus can be used to estimate probability distributions for wheat yield. The data are assumed to follow triangular distributions, due to the limited results available. A triangular probability distribution requires three values, values for the highest, lowest and most likely events. The values for the wheat yields for each zone are shown in Table 1. Also, the yields for each zone are correlated to ensure that temporal variability in yields across zones was not completely random, but were related to yields in the other zones as would be expected. The correlations of wheat yields are shown in Table 2.

Table 1: Distributions of yields and protein levels across management zones, and the distribution of wheat price.

\begin{tabular}{|c|c|c|c|}
\hline Variable & Unit & Distribution & Values \\
\hline \multicolumn{4}{|c|}{ Zone Management Yields } \\
\hline Low zone & T/ha & Triangular & $1.00,1.50,2.20^{1}$ \\
\hline Medium zone & T/ha & Triangular & $1.50,3.00,4.25$ \\
\hline High zone & T/ha & Triangular & $2.80,3.75,5.00$ \\
\hline \multicolumn{4}{|c|}{ Wheat Yields No Zone Management (Average inputs used across all zones) } \\
\hline Low zone & T/ha & Triangular & $1.00,1.60,2.00$ \\
\hline Medium zone & T/ha & Triangular & 1.50. $3.00,4.25$ \\
\hline High zone & T/ha & Triangular & $2.60,3.40,4.60$ \\
\hline \multicolumn{4}{|c|}{ Zone Management Protein Levels } \\
\hline Low zone & $\%$ & Triangular & $8.80,10.10,10.80$ \\
\hline Medium zone & $\%$ & Triangular & $9.60,11.20,12.70$ \\
\hline High zone & $\%$ & Triangular & 10.50. $12.40,13.75$ \\
\hline \multicolumn{4}{|c|}{ Protein Levels No Zone Management (Average inputs used across all zones) } \\
\hline Low zone & $\%$ & Triangular & $9.50,10.65,12.00$ \\
\hline Medium zone & $\%$ & Triangular & $9.60,11.20,12.70$ \\
\hline High zone & $\%$ & Triangular & $9.60,11.75,13.00$ \\
\hline
\end{tabular}


Table 2: Correlations of wheat yields and protein concentrations across management zones.

\begin{tabular}{|c|c|c|c|}
\hline \multicolumn{4}{|c|}{ Wheat yield correlations } \\
\hline & High & Medium & Low \\
\hline Lowest expected yield & 1.00 & 0.90 & 0.70 \\
\hline Most expected yield & & 1.00 & 0.50 \\
\hline Highest expected yield & & & 1.00 \\
\hline \multicolumn{4}{|c|}{ Wheat protein correlations } \\
\hline & High & Medium & Low \\
\hline Lowest expected protein percentage & 1.00 & 0.90 & 0.70 \\
\hline Most expected protein percentage & & 1.00 & 0.50 \\
\hline Highest expected protein percentage & & & 1.00 \\
\hline
\end{tabular}

Australian wheat producers are paid on quantity and quality for the grain delivered, the most valuable quality parameter being grain protein. Data from the same trials as the quantity distributions were derived from were used to estimate the distributions for protein yield as shown in Table 1. Protein levels in the low zone, when average inputs are used, are higher than under zone management due simply to the extra nitrogen available that the plant converts to grain protein. Similar to the grain yields protein yields were also correlated across management zones and the protein correlations are also reported in Table 2.

\section{Grain prices, premiums and discounts.}

A mean gross price of $\$ 219 / \mathrm{t}$ used in the model was the average price for Australian Premium White delivered to Geraldton port, the closest port, over the past 10 years; and with a delivery charge of $\$ 10 / t$ and other ancillary fees of $\$ 30 / t$ yielded a mean net farm gate price of $\$ 179 / \mathrm{t}$. The standard deviation of the wheat price was $\$ 29 / \mathrm{t}$. Due to the logarithmic nature of the real options model the wheat distribution is assumed to be log-normal, with the above parameters, i.e. wheat price is distributed as log-normal with mean $=219$ and variance $=841$. Wheat producers also receive a premium or discount for wheat delivered with over or under the base protein level of $10 \%$. For grain with a protein level under $10 \%$ a discount of $\$ 1.50 / \mathrm{t}$ is incurred, for protein levels between $10.5 \%$ and $11.5 \%$ a premium of $\$ 2 / \mathrm{t}$ is paid, between $11.5 \%$ and $12.5 \%$ the premium is $\$ 3 / \mathrm{t}$ and for over $12.5 \%$ the premium is $\$ 4 / \mathrm{t}$.

\section{Fertiliser levels and variable costs}

The use of all inputs, except for fertiliser, is fixed across all zones and all scenarios, as changes in fertiliser levels were the only treatments used in the experiments reported. The levels of these inputs are typical for the region in which the case study farm is located. Fertiliser inputs in the conventional system were set at $80 \mathrm{~kg} / \mathrm{ha}$ of di-ammonium phosphate with zinc and copper (DAPZC) and $120 \mathrm{~kg} / \mathrm{ha}$ of urea. In the zone management system the fertiliser levels varied across zones. For the low production zone the application rate for fertilisers were $20 \mathrm{~kg} / \mathrm{ha}$ of DAPZC and $60 \mathrm{~kg} / \mathrm{ha}$ of urea, in the medium production zone the 
fertiliser rates were the same as the conventional system, $80 \mathrm{~kg} / \mathrm{ha}$ of DAPZC and $120 \mathrm{~kg} / \mathrm{ha}$ of urea, and in the high production zone the rates were $160 \mathrm{~kg} / \mathrm{ha}$ of DAPZC and $160 \mathrm{~kg} / \mathrm{ha}$ of urea. Fertiliser costs are $\$ 558 / \mathrm{t}$ and $\$ 490 / \mathrm{t}$ delivered on farm for DAPZC and urea, respectively. The total variable costs for all other inputs, excluding fertiliser and machinery operating costs are \$114.80/ha. Again costs for the conventional system are increased by 5\% due to overlap.

Gross margins for each zone were estimated as follows \$296/ha, \$224/ha, and $\$ 13 /$ ha for the zone management scenarios for the high, medium and low productivity zones, respectively. The gross margins for the conventional system were \$293/ha, \$251/ha, and $-\$ 35 / h a$, in the high, medium and low zones. Note that the farm manager is "unaware" of the difference in returns per zone as the farm is managed based on average inputs. Hence, even though losses are made on the low zone, averaging across the zones camouflages the losses.

\section{RESULTS AND DISCUSSION}

\section{Non-stochastic net present value.}

Beginning with the equal area model, EA, a non-stochastic NPV of \$268, 969 for the controlled traffic precision system and for the conventional system an NPV of $\$ 101,009$ was estimated (Table 3). The Marshallian trigger values, or the hurdle rates, calculated as $\rho \mathrm{M}$, where $\mathrm{M}$ is the investment value, are $\$ 126,279$ and $\$ 129,150$, for the precision and conventional systems, respectively. Using this information alone, the decision maker would invest in the precision agriculture system, but not undertake the investment in conventional system. As the area of highly productive land increases the NPV of each investment increased, as expected due to the higher gross margins per hectare for the more productive land, even though more inputs are used. In the $50 \mathrm{H}$ scenarios both the conventional and precision systems exceed the trigger values and the producer could invest in either system to generate positive returns on the investment in machinery. Conversely, in the scenarios where the major soil type is the low productive soils, neither investment exceeds the Marshallian trigger values; hence neither option would yield positive returns on investment and should not be undertaken.

\section{Real options and modified trigger values}

When uncertainty entered into the analysis through the variance of the logarithm of expected returns, the expected net present value (eNPV) changed in various directions. The outcomes for the real options analysis are presented in Table 3. For the controlled traffic systems, in all relative-area models, the eNPV increased above the non-stochastic NPV by between $10 \%$ and $76 \%$. The smaller change in the $50 \mathrm{H}$ model and the larger change in the $20 \mathrm{H}$ model, the change in NPV in the EA model was approximately $19 \%$. However, in the conventional systems the changes from NPV to eNPV were variable. In the EA and $20 \mathrm{H}$ models, the eNPV was lower than the non-stochastic NPV by $9 \%$ and $15 \%$ respectively, but in the $50 \mathrm{H}$ model the eNPV was higher than the NPV by $7 \%$. 
Table 3: Net present value, expected Net Present Value (eNPV), standard deviation, Marshallian and modified trigger values, and the modified hurdle rate estimated in the real options analysis for each relative area model, and the models when the low zone was taken out of production.

\begin{tabular}{|c|c|c|c|c|c|c|}
\hline $\begin{array}{l}\text { Machinery } \\
\text { System }\end{array}$ & NPV & $\mathrm{eNPV}^{1}$ & $\begin{array}{l}\text { Standard } \\
\text { deviation } \\
\text { of eNPV }\end{array}$ & $\begin{array}{l}\text { Marshallian } \\
\text { Trigger }\end{array}$ & $\begin{array}{l}\text { Modified } \\
\text { Trigger }\end{array}$ & $\begin{array}{l}\rho^{\prime} \\
\text { Modified } \\
\text { Hurdle Rate }\end{array}$ \\
\hline \multicolumn{7}{|l|}{ Base Models } \\
\hline \multicolumn{7}{|c|}{ Equal Area (EA) } \\
\hline Precision & $\$ 268,969$ & $\$ 319,731$ & $\$ 226,296$ & $\$ 126,279$ & $\$ 160,169$ & $11.42 \%$ \\
\hline Conventional & $\$ 101,009$ & $\$ 91,635$ & $\$ 230,035$ & $\$ 129,150$ & $\$ 167,491$ & $11.67 \%$ \\
\hline \multicolumn{7}{|c|}{50 \% High, 30\% Medium, 20\% Low (50H) } \\
\hline Precision & $\$ 568,935$ & $\$ 623,637$ & $\$ 266,269$ & $\$ 126,279$ & $\$ 159,757$ & $11.39 \%$ \\
\hline Conventional & $\$ 445,958$ & $\$ 479,284$ & $\$ 268,242$ & $\$ 129,150$ & $\$ 163,734$ & $11.41 \%$ \\
\hline \multicolumn{7}{|c|}{20 \% High, 30\% Medium, 50\% Low (20H) } \\
\hline Precision & $-\$ 66,620$ & $-\$ 16,406$ & $\$ 196,940$ & $\$ 126,279$ & $\$ 163,844$ & $11.68 \%$ \\
\hline Conventional & $-\$ 290,184$ & $-\$ 335,690$ & $\$ 199,056$ & $\$ 129,150$ & $\$ 180,463$ & $12.58 \%$ \\
\hline \multicolumn{7}{|l|}{ No Low } \\
\hline \multicolumn{7}{|c|}{ Equal Area (Low zone not sown, EANL) } \\
\hline Precision & $\$ 236,373$ & $\$ 256,130$ & $\$ 201,825$ & $\$ 126,279$ & $\$ 157,123$ & $11.20 \%$ \\
\hline Conventional & $\$ 188,240$ & $\$ 215,447$ & $\$ 208,159$ & $\$ 129,150$ & $\$ 159,713$ & $11.13 \%$ \\
\hline \multicolumn{7}{|c|}{50 \% High, 30\% Medium, 20\% Low zone not sown (50HNL) } \\
\hline Precision & $\$ 549,377$ & $\$ 577,067$ & $\$ 253,614$ & $\$ 126,279$ & $\$ 158,639$ & $11.31 \%$ \\
\hline Conventional & $\$ 525,288$ & $\$ 593,492$ & $\$ 258,429$ & $\$ 129,150$ & $\$ 160,093$ & $11.16 \%$ \\
\hline \multicolumn{7}{|c|}{$20 \%$ High, 30\% Medium, 50\% Low zone not sown (20HNL) } \\
\hline Precision & $-\$ 115,515$ & $-\$ 109,133$ & $\$ 147,845$ & $\$ 126,279$ & $\$ 155,040$ & $11.11 \%$ \\
\hline Conventional & $-\$ 159,337$ & $-\$ 150,982$ & $\$ 157,854$ & $\$ 129,150$ & $\$ 159,419$ & $11.11 \%$ \\
\hline
\end{tabular}

${ }^{1} \mathrm{eNPV}$ is the expected net present value from the real options analysis

The variance of returns also affected the hurdle rate, the minimum rate of return for the investment to generate positive returns. In all cases, controlled traffic or conventional systems, the modified hurdle rate increased. The size of the changes ranged from $27 \%$ to $40 \%$ (see Table 3 ). The smaller changes occurred in the model where the high producing area accounted for $50 \%$ of the total area sown to wheat $(50 \mathrm{H})$, indicating that the returns in this area have a lower variance of returns than the other two areas. This is confirmed when looking at the change in hurdle rates for the $20 \mathrm{H}$ model. In this case the hurdle rate increased by 2.68 and 3.58 percentage points for the precision system and the conventional system, respectively, from the base hurdle rate of $9 \%$. As a consequence of the increasing hurdle rates the trigger values increased from the Marshallian to the modified trigger values. The impact of changes to the trigger values did not change the decisions determined in the basic NPV models, i.e. a split decision in the EA models, invest in either type of system for the $50 \mathrm{H}$ models, and invest in neither system in the $20 \mathrm{H}$ model.

\section{Sensitivity Analysis}

Hyde et al (2003) constructed a matrix of changes in the modified trigger value and hurdle rate due to changes in either the logarithm of the variance of returns or the base hurdle rate to test the sensitivity of the model to these parameters. Rather 
than take that approach, a set of alternative scenarios was run where it was assumed the producer had some knowledge of soil types, and the low production potential zone was taken out of production due to the low positive to negative returns generated by this zone. But it was assumed the producer was still uncertain as to which of the two, the precision system or the conventional system, was a better investment.

The results of this analysis are presented in the second half of Table 3. Several points arise from the results of removing the low zone from production. The first is that in all three relative area models the expected NPV for the conventional system all increase from the models where all the cropping area is included in the model runs, and in the case of the conventional system in the equal area model, the NPV and expected NPV all increased over the modified trigger value. This indicates that now these systems are potential investment alternatives, although they still generate lower returns than the precision agriculture system.

The second point to note is that the NPV and expected NPV for the precision agriculture system fell when the low zone was removed. This is not surprising as the gross margin of the low zone although low was positive and taking this zone out of production would be expected to reduce investment returns. However, removing the low zone from production in all models, either precision agriculture or conventional, reduced the variance of returns and thereby reduced the hurdle rates. In some cases this reduction was marginal, for example in the $50 \mathrm{H}$ with the low zone the modified hurdle rate was $11.39 \%$ and $11.41 \%$ for the precision and conventional systems, respectively. However, when the low zone is taken out of production the modified hurdle rates fell to $11.31 \%$ and $11.16 \%$ for the precision and conventional systems, respectively. Whereas, when looking at the $20 \mathrm{H}$ models the modified hurdle rates fall from $11.68 \%$ and $12.58 \%$ for the precision and conventional systems, respectively, to $11.11 \%$ for both systems. This indicates that the low production zone is increasing the variability of returns due to the higher inherent variability of yields in that zone. The reduction in hurdle rates and the subsequent falls in the modified trigger values did not change the investment decisions derived in the analysis with the low zone in production, although as mentioned previously the conventional system in the equal area model does become a feasible option, but this is due to an increase in NPV rather than the fall in the modified trigger value.

One final point to note is the value of knowing the production and income potential of the management zones in the production system, even if the producer chooses not to undertake the investment in the precision agriculture system. The value of this knowledge is demonstrated in the comparison of the systems with and without the low zones in production. If the producer chooses not to invest in the precision agriculture system, but still undertake some soil testing to determine the areas of each type of soil within the production system, then the value of this knowledge would be the difference between the expected NPV for the conventional system with and without the low zone in production, less the costs of soil sampling. 


\section{CONCLUSIONS}

The purpose of this research was to investigate the impacts of uncertainty on a machinery investment decision of a grain producer in the wheatbelt of Western Australia. As standard investment analysis tools, such as net present value, do not take into account uncertainty a real options theory model was utilised. The effect of uncertainty or irreversibility on the value of the investment indicate that a rate of return between 2 and 3 per cent higher than standard discount or hurdle rate used in NPV analysis is required for the investment to transpire. In all cases the expected NPV generated by the real options model for the precision system were greater than those for the conventional system, although as the relative proportion of high productivity land increased the difference in expected NPV between the two systems diminished. Also, as the proportion of low production land increased the viability of the investment decreased.

In several of the scenarios studied both systems would be considered as feasible alternative investments as the expected NPV was greater than zero. This indicates that the income generated exceeds the costs of the investment, hence the conclusion that either investment would be a feasible alternative. Also, the value of information can be estimated using real options analysis. This is helpful in understanding the investment decisions made by some producers, although they may not invest in precision agricultural machinery, i.e. variable rate technology or matched machinery widths, they use the information generated through thinking about precision agriculture, such as soil testing, to improve the returns of the farming system.

One point to remember is that in this analysis it was assumed that all machinery investment occurred at the beginning of the analysis period. This was done to simplify the analysis, due to multiple combinations of investment times and machinery choices. This is an area of future research where the timing of the purchase of individual machinery pieces could be considered in a dynamic stochastic model. 


\section{REFERENCES}

ABARE (Australian Bureau of Agricultural and Resource Economics). 2006. Australian Commodity Statistics 2006. Canberra.

Babcock, B.A., and G. R. Pautsch. 1998 Moving from uniform to variable fertilizer rates on Iowa corn: Effects on rates and returns. J. Agric. and Res. Econ. 23:385-400.

Blackwell, P, B. Webb, J. Lemon, and G. Reithmuller. 2003. Tramline farming: pushing controlled traffic for Mediterranean farming systems in Australia. Paper presented to the $16^{\text {th }}$ International Soil and Tillage Research Organisation Conference, Brisbane.

Dixit, A.K. 1992 Investment and Hysteresis. J. Econ. Perspectives. 6:107-132.

Dixit, A.K., and R. S. Pindyck. 1994. Investment under Uncertainty. Princeton University Press, Princeton NJ.

Hyde, J., J. R. Stokes, and P. D. Engel. 2003 Optimal investment in an Automatic Milking System: An application of real options. Ag. Fin. Rev. 63:75-92.

Isbister, B., D. Forrester, and P. Tozer. 2006 Management zones must be evaluated over seasons. In: GRIST Manual 2006, edited by Lloyd O’Connell, http://www.grdc.com.au/growers/oft/oft_search/docs/wa/2006/wfbindi1.htm Accessed November 16, 2007.

James, I. T., and R. J. Godwin. 2003. Soil, Water and Yield Relationships in developing Strategies for the Precision Application of Nitrogen Fertiliser to Winter Barley. Biosys. Eng. 84:467-480.

NSWDPI (2007). Guide to tractor and implement costs. http://www.agric.nsw.gov.au/reader/machine+water/242kw-2007.pdf Accessed November 16, 2007.

Purvis, A., W. G. Boggess, C. B. Moss, and J. Holt. 1995. Technology adoption decisions under irreversibility and uncertainty: An ex ante approach. Am. J. Agric. Econ. 77:541-551. 
Sonka, S.T., and G. F. Patrick. 1984. Risk management and decision making in agricultural firms. P. 95-115. In: PJ Barry (ed) Risk management in agriculture. Iowa State University Press, Ames, IA.

Tozer, P.R. 2006. Depreciation Rates for Australian Tractors and Headers - Is Machinery Depreciation a Fixed or Variable Cost? Australian Agribusiness Perspectives. Paper 70.

Webb, B., D. Shepherd, D. Forrester, and P. Tozer. (2005) Zone management improves profit on sandplain. In: GRIST - 2005 National Farm Groups' Manual, edited by Lloyd O’Connell, (Australian Grain, Toowoomba, Australia), p. 101-104. 